\title{
Patients Satisfaction and Outcome of Fistulotomy versus Fistulectomy for Low Anal Fistula
}

\author{
Aly Saber \\ Department of General Surgery, Port-Fouad General Hospital, Port-Fouad, Egypt \\ Email address: \\ Alysaber54@gmail.com \\ To cite this article: \\ Aly Saber. Patients Satisfaction and Outcome of Fistulotomy versus Fistulectomy for Low Anal Fistula. Journal of Surgery. Special Issue: \\ Gastrointestinal Surgery: Recent Trends. Vol. 4, No. 2-1, 2016, pp. 15-19. doi: 10.11648/j.js.s.2016040201.14
}

\begin{abstract}
Introduction: Anal fistulae are still negatively influencing the patient's quality of life by causing minor pain, social hygienic embarrassment, and in severe cases, frank sepsis. Although a number of surgical techniques have been proposed to treat this condition, there is still no single ideal technique for the treatment of this disease. Generally, fistulectomy is an adequate surgical procedure for the treatment of a simple or low transsphincteric fistula while others reported that fistulotomy continues to have excellent results. Patients and Methods: This study represented parallel prospective randomized clinical trial where 200 patients were divided randomly into two main groups; A and B. Group A patients were subjected to fistulotomy and those of group B were subjected to fistulectomy for low anal fistulae. The study included all patients having low anal fistulae complicating perianal abscesses. Patients with high fistulae and patients with multiple external openings were excluded. The primary end point was anal incontinence and the secondary end points were time off from work, postoperative pain, wound discharge, wound healing and patients' satisfaction. Results: The mean operative time, time taken for wound discharge to cease and time taken for complete healing was significantly less in patients of group A. Regarding the occurrence of fecal incontinence, no permanent cases were reported in our series but temporary incontinence was observed in 2 patients in fistulotomy group while in fistulectomy group there were 4 patients. Therefore, the overall patient satisfaction mean values were $90.6 \pm 8.87$ and $85.6 \pm$ 13.2 for patients in group A and B respectively with statistically insignificant distribution. Conclusion: Fistulotomy could be used as a primary treatment of low anal fistula as being safe and simple to perform with good patient's satisfaction as regard postoperative pain and outcome.
\end{abstract}

Keywords: Low Anal Fistula, Fistulotomy, Fistulectomy, Patient's Satisfaction

\section{Introduction}

Anal fistula is a common benign condition describing an abnormal communication between the anorectum and the perianal skin, which usually develops after acute anorectal abscess. Anal fistulae are still negatively influencing the patient's quality of life by causing minor pain, social hygienic embarrassment, and in severe cases, frank sepsis [1]. Although a number of surgical techniques have been proposed to treat this condition, there is still no single ideal technique for the treatment of this disease [2]. There are two important problems in the surgical treatment of an anal fistula, recurrence and incontinence, and these two factors affect the surgical outcome [3]. Generally, fistulectomy is an adequate surgical procedure for the treatment of a simple or low transsphincteric fistula [4] while others reported that fistulotomy continues to have excellent results [5].

\section{Patients and Methods}

\subsection{Patients}

This study represented parallel prospective randomized clinical trial where patients were divided randomly into two main groups; A and B. Group A patients were subjected to fistulotomy and those of group B were subjected to fistulectomy for low anal fistulae. All of our patients were gentlemen with total number was 200 patients; 100 for each group, their ages ranged between 21- 55 years. The study started from January 2007 to December 2010 and included all patients having low anal fistulae complicating perianal abscesses. Patients with high fistulae and patients with multiple external openings were excluded. Written consents were obtained from all patients before the study. The steps of both operative interferences were explained to all patients. 
The local ethics committee had approved all operative procedures. Ethical approval for this study was granted by the ethical review committee under supervision of the general director of Port- Fouad general hospital, Port-Fouad, Port-Said, Egypt.

\subsection{Sample Size}

In general, the temporary anal incontinence in fistulotomy patients in previous studies is about $2 \%$ and those in fistulectomy patients is about $12 \%$ [6]. Calculation of the sample size included the number of participants to be recruited for the study using the mathematical equation. The authors used the following equation to calculate the minimum number required to reliably answer the research question and the number, $\mathrm{N}=\sim 100$ patients for each group, as given by:

$P^{I}$ represents the temporary anal incontinence in fistulotomy patients in previous studies $=2 \%$ and $P^{2}$ represents the temporary anal incontinence in fistulectomy patients in previous studies $=12 \%$ [6]. The sample size was calculated according to the equation [7].

$$
N=\frac{K *\left(p_{1} q_{1}+p_{2} q_{2}\right)}{d^{2}}=\sim 100 \text { patients }
$$

Where:

$\mathrm{q} 1=(1-\mathrm{p} 1), \mathrm{q} 2=(1-\mathrm{p} 2)$ and $\mathrm{d}=(\mathrm{p} 1-\mathrm{p} 2)$

$\mathrm{K}=$ constant, which depends on: alpha and beta levels, where alpha $=0.05$ and beta $=0.1$. Then $\mathrm{K}=8.6$.

\subsection{Randomization}

Randomization was performed prior to study commencement as follows: Opaque envelopes were numbered sequentially from 1 to 200 . A computer-generated table of random numbers was used for group assignment; if the last digit of the random number was from 0 to 4 , assignment was to Group A (fistulotomy), and if the last digit was from 5 to 9 , assignment was to Group B (fistulectomy). The assignments were then placed into the opaque envelopes and the envelopes sealed. As eligible participants were entered into the trial, these envelopes were opened in sequential order to give each patient his or her random group assignment. The envelopes were opened by the operating surgeon after patient consent and just prior to the surgery.

\subsection{Surgical Teams \& Study Sites}

Operations were performed in Port-Fouad general hospital, Port-Fouad, Port-Said, Egypt.

\subsection{Operative Techniques}

Really our patients were oriented to the type of operation and the other observers also were aware to operative techniques of the study groups.

1. In the fistulotomy with marsupialization, the fistula tract was laid open over the grooved probe placed in the tract. After the fistula tract had been laid open, the tract was curetted and examined for secondary extensions. Wound edges were secured for proper hemostasis to achieve.

2. In the fistulectomy, a circular skin incision completely surrounding and encircling the external opening was made. The incision was deepened through the subcutaneous tissue, and the tract was removed from surrounding tissues. While the tract was being removed, attention was paid to identifying secondary tracts, if any. Hemostasis was achieved.

\subsection{End Points}

The primary end point of the study was anal incontinence, assessed by using the Fecal Incontinence Severity Index (FISI), that allow patients to record the frequency of accidental leakage with gas, mucus, liquid, and/or solid stool:

1) No accidental leakage from anus (no fecal/flatal incontinence [no FI/FL]),

2) Leakage of gas only (isolated flatal incontinence only [isolated FL]), or

3) Accidental leakage of mucus, liquid or solid stool with or without leakage of gas (fecal incontinence [FI] with or without flatal incontinence) [8].

The secondary end points were time off from work, defined as the number of days between the day of surgery and the first day a patient returned to work [7], postoperative pain, wound discharge, wound healing and patients' satisfaction. Regarding the postoperative pain, we considered the Visual Analog Scale pain score of a 3 -scale system; Mild (1-4) $=1$ point, moderate $(5-7)=2$ points, severe $(8-10)=3$ points.

Postoperative wound discharge was defined as a non-infected sero-sanguinous secretion coming from the open wound while complete healing of the postoperative wound was defined as full epithelialization of the wound [6]. Patient's satisfaction was measured according to occurrence of incontinence, the severity of postoperative pain, wound discharge and healing time.

Patients in both groups were administered ciprofloxacin and metronidazole as perioperative antibiotics for a total duration of three days. Diclofenac sodium (50 mg twice a day) was prescribed as an analgesic for a total duration of 3 days. The patients were discharged on the first postoperative day. The patients were advised regarding oral medication, maintenance of local hygiene, sitz bath after defecation, dressings, and regular follow-ups.

\subsection{Statistical Analysis}

The statistical tests were run on a compatible personal computer using the Statistical Package for Social Scientists (SPSS) for windows 15. Chi-square distribution was used for studying the frequencies of recurrence, pain, hospital stay and postoperative complications. The values were expressed as means \pm standard errors of deviation. The mean values of the groups were compared by one-way analysis of variance (ANOVA) and paired comparisons of the groups were done using the paired student $t$ test. $\mathrm{P}<0.05$ was considered significant. 


\section{Results}

A total of 200 anal fistula surgeries were performed 100 for both fistulotomy and fistulectomy. Concerning the demographic data, there was no statistical significant difference between the two groups regarding age, sex and body mass index. There was neither operative nor 30 days postoperative mortality.

The operating time for the procedure was calculated from the start of the dye test to the beginning of dressing of the postoperative wound. The mean operative time in patients of group A was $27 \pm 1.74$ minutes and that for patients of group B was $37 \pm 1.78$ minutes and this difference is considered to be extremely statistically significant $\{\mathrm{P} \leq 0.0001\}$.

Regarding the occurrence of fecal incontinence, no permanent cases were reported in our series but temporary incontinence was observed in 2 patients in fistulotomy group while in fistulectomy group there were 4 patients. According to Fecal Incontinence Severity Index, none of our patients showed fecal incontinence and only the two of group A as well as other two of group B were temporarily incontinent to gases that subsided gradually and the other four patients of group B showed temporary incontinence to mucus. We detected that $98 \%$ and $96 \%$ of group A and B respectively were satisfied of the treatment maneuver.

Early post-operative pain score using Visual Analogue scale was traced according to table 1 . Analog Scale pain score was mild in 10 patients of group A and in 8 patients in group B, moderate in 35 patients and 30 patients and severe 5 patients and 12 patients in group $\mathrm{A}$ and $\mathrm{B}$ respectively. Regarding post-operative pain, we detected that $5 / 100$ patients in group A and 12/100 patients in group B were unsatisfied of the treatment maneuver.

Table 1. Mean values of Visual Analogue scale in early postoperative period in both groups.

\begin{tabular}{llllll}
\hline Group & Mean & $\begin{array}{l}\text { Standard } \\
\text { deviation }\end{array}$ & T value & df & P value \\
\hline A & 4.8 & \pm 4.36 & 2.022 & 198 & 0.0445 \\
B & 6.18 & \pm 5.25 & & & \\
\hline
\end{tabular}

The postoperative non-infected sero-sanguinous wound discharge was observed and studied. The discharge became serous only by time until completely ceased. The time taken for wound discharge to cease was 2-3 weeks with mean value $2.4 \pm 0.5$ and $3-5$ weeks with mean value $3.95 \pm 0.7$ in group A and $\mathrm{B}$ respectively with statistically insignificant distribution $\{P \leq 0.0001\}$. In case of postoperative wound discharge, we detected that 18/ 100 patients in group A and 26/100 patients in group B were unsatisfied of the treatment maneuver.

The time taken for wound to heal completely according to the proposed protocol in methodology was 3-6 weeks with mean value $4.28 \pm 1$ and $4-8$ weeks with mean value $5.96 \pm 1.4$ in group A and B respectively with statistically insignificant distribution $\{P \leq 0.0001\}$ [ table 2]. As regard the time taken for complete wound healing, we detected that $20 / 100$ patients in group A and 30/100 patients in group B were unsatisfied of the treatment maneuver.
Table 2. Showed the mean time taken for wounds to cease discharge and to heal completely in both groups.

\begin{tabular}{lllllll}
\hline Item & & Group A & Group B & t value & df & P value \\
\hline \multirow{2}{*}{ Discharge } & Mean & 2.4 & 3.95 & & & \\
& SD & \pm 0.5 & \pm 0.7 & & & \\
\multirow{2}{*}{ Healing } & Mean & 4.28 & 5.96 & 4.8824 & 48 & $P \leq$ \\
& SD & \pm 1 & \pm 1.4 & & & 0.0001 \\
\hline
\end{tabular}

Patient satisfaction was traced in our study as the sum of individual satisfaction for each parameter according the questionnaire signed by the patients themselves as shown in table 3. In case of anal incontinence, there were $98 \%$ and $96 \%$ of patients in group A and B seemed satisfied. There were 5/100 patients in group A and 12/100 patients in group B suffering from higher pain score; accordingly, we observed that $95 \%$ and $88 \%$ of patients in group A and B seemed satisfied regarding their post-operative pain. For the time taken for wound discharge to cease and that taken for wound to heal completely, patient satisfaction was shown and studied. Therefore, the overall patient satisfaction mean values were $90.6 \pm 8.87$ and $85.6 \pm 13.2$ for patients in group A and B respectively with statistically significant distribution $\{\mathrm{P} \leq 0.0019\}$

Table 3. The overall patient satisfaction mean values in both groups $A$ and $B$.

\begin{tabular}{llll}
\hline Parameters & Group A & Group B & Significance \\
\hline Incontinence & 98 & 96 & \\
Pain score & 95 & 88 & \\
Wound discharge & 82 & 74 & $\mathrm{P} \leq 0.0019$ \\
Wound healing & 80 & 70 & $\mathrm{~T}=3.144$ \\
Recurrence & 98 & 100 & $\mathrm{df}=198$ \\
Total: Mean \pm SD & $90.6 \pm 8.87$ & $85.6 \pm 13.2$ & \\
\hline
\end{tabular}

\section{Discussion}

In the present study, the mean operative time for fistulotomy was significantly shorter than that for fistulectomy coming in concordance with other studies of same interest [9] while other researchers found no significant differences between the operating times owing to fistulectomy operation requires dissection of the fistula tract from the surrounding tissues, followed by coagulation of bleeding to control homeostasis. During a fistulotomy with marsupialization, the fistula tract is laid open, so dissection of the fistula tract is not required, but several minutes are required to suture the edges of the laid-open fistula tract to the skin incision $[6,10,11]$.

Regarding the occurrence of fecal incontinence in the present study according to Fecal Incontinence Severity Index [8] was $2 \%$ patients in fistulotomy and $4 \%$ in fistulectomy group that came in agreement of this recent study from Japan that reported temporary minor incontinence of $4 \%$ of fistulectomy patients [12]. Another recent study found that fistulectomy is associated with a higher rate of incontinence $50 \%$ versus $25 \%$ in fistulotomy since muscle separation necessarily occurs after excision of the complete tract [13].

On the other hand, some researchers reported that none of their patients developed anal incontinence $[6,10,14,15]$.The small sample size is one of the limitations of some of these studies. Another limitation is the large number of low fistulae 
in both groups of patients because surgical treatment of a low fistula is unlikely to compromise continence and recurrence as recurrence is more common in high fistula. This may be the reason for the better functional outcome seen in our patients in both groups [10].

The VAS score was significantly higher in the early postoperative period in fistulectomy group than in fistulotomy group in our study and others of same interest [11, 16, 17]. Sahakitrungruang and his colleagues stated that there was a significant difference in the number of patients who needed pethidine injection of the fistulectomy group versus the fistulotomy group. On the other hand, other studies showed no significant difference between the two groups in the mean postoperative VAS score at various follow-up times [6, 11, 18].

Wound discharge was observed being significantly of shorter duration in fistulotomy group than in fistulectomy group in the present study and in similar works of same interest $[11,13]$. The mean healing time was statistically significantly longer in fistulotomy group than in fistulectomy group which similar to findings from other randomized clinical trials $[6,13,18]$. This finding can be explained by the fact that the mean operation wound size in these studies was smaller in fistulotomy group than in fistulectomy group [13]. The healing times in days and weeks were nearly similar in our study and others of same interest [9-11, 17]. In fistulectomy the whole track and adjacent tissue is removed resulting in larger wound followed by longer healing time [19]. In fistulotomy, lesser amount of tissue is excised resulting in earlier healing time as compared to fistulectomy [20].

According to previous studies, fistula recurrence developed in $4.5-6 \%$ of patients treated with fistulotomy and in $6.8 \%$ of fistulotomy patients $[9,12,21,22]$ while in other studies, no patient developed recurrence during the follow-up period of twelve weeks $[6,11]$. However, the duration of observation in the present study was not sufficient to draw any definite correlation with respect to recurrence [11]. Qureshi and his colleagues [22] reported recurrence in $4.44 \%$ of patients following fistulotomy and no recurrence following fistulectomy with no significant differences and these observations came in concordance with our data

Patient satisfaction after surgery for anal fistula depends on factors like period of hospitalization, postoperative pain and bleeding, return to routine activity, wound care, wound healing time, interference with the anal continence and recurrence [17]. The majority of patients subjected to surgery for anal fistula attributed their dissatisfaction to recurrence and anal incontinence following surgery [23].

In the present study, our parameters for patient's satisfaction were postoperative incontinence, fistula recurrence, pain score, time for wound discharge to cease and time for wound to heal completely. Studies concerned with patients' satisfaction after surgery for anal fistula documented that the extents of adverse effects of surgery on the physical, social and sexual lives of the fistulotomy patients were less than those of fistulectomy patients $[6,23]$. Our data came in agreement with these reports where more than $90 \%$ of the fistulotomy patients were satisfied with their treatment option.

\section{Conclusion}

Fistulotomy could be used as a primary treatment of low anal fistula as being safe and simple to perform with good patient's satisfaction as regard postoperative pain and outcome. Fistulotomy could be used as a primary treatment of low anal fistula owing to shorter operative time, less time for wound discharge to cease and less time for wound to heal time compared with those for fistulectomy.

\section{References}

[1] Zubaidi AM. Anal fistula. Past and present. Saudi Med J. 2014; 35(9): 937-44.

[2] Kim do S. Advancement flap for the treatment of a complex anal fistula. Ann Coloproctol. 2014; 30(4): 161-2. doi: 10.3393/ac.2014.30.4.161.

[3] Ertem M, Gok H, Ozveri E, Ozben V. Application of advancement flap after loose seton placement: a modified two-stage surgical repair of a transsphincteric anal fistula. Ann Coloproctol. 2014; 30(4): 192-6.

[4] Jacob TJ, Perakath B, Keighley MR. Surgical intervention for anorectal fistula. Cochrane Database Syst Rev. 2010, 12; (5): CD006319.

[5] Hall JF, Bordeianou L, Hyman N, Read T, Bartus C, Schoetz D, Marcello PW. Outcomes After Operations for Anal Fistula: Results of a Prospective, Multicenter, Regional Study. Dis Colon Rectum. 2014; 57(11): 1304-1308.

[6] Jain BK, Vaibhaw K, Garg PK, Gupta S and Mohanty D. Comparison of a Fistulectomy and a Fistulotomy with Marsupialization in the Management of a Simple Anal Fistula: A Randomized, Controlled Pilot Trial. J Korean Soc Coloproctol. 2012; 28(2): 78-82.

[7] Saber A, Ellabban GM, Gad MA and Elsayem K. Open preperitoneal versus anterior approach for recurrent inguinal hernia: a randomized study. BMC Surgery 2012, 12:22 doi: 10.1186/1471-2482-12-22.

[8] Imhoff LR, Brown JS, Creasman JM, Subak LL, Van den Eeden SK, Thom DH, Varma MG, Huang AJ. Fecal incontinence decreases sexual quality of life, but does not prevent sexual activity in women. Dis Colon Rectum. 2012; 55(10): 1059-65.

[9] Kamal ZB. Fistulotomy Versus Fistulectomy As a Primary Treatment of Low Fistula in Ano. Iraq Postgrad Med J, 2012: 11(4): 510-515.

[10] Sandhya A, Rasool S, Parveen S. Marsupialization for Simple Fistula in Ano. J Surg Pakistan (International). 2013, 18 (1): 12-16.

[11] Chalya PL, Mabula JB. Fistulectomy versus fistulotomy with marsupialisation in the treatment of low fistula-in- ano: a prospective randomized controlled trial. Tanzan J Health Res. 2013, 15 (3): 1-8.

[12] Abe T, Kunimoto M, Hachiro Y, EbisawaY, Hishiyama H and Abe S. Open fistulectomy with sphincter fixation for anal fistula. Open J Gastroenterology. 2013, 3: 223-226. 
[13] Sharma D, Pipariya PR, Gupta S, Gupta A and Chopra N. Fistulectomy or Fistulotomy: Better Approach in Fistula-In-Ano. Sch. J. App. Med. Sci., 2014; 2(1B): 202-204.

[14] Abu Salem OT. Fistulectomy and fistulotomy for low anal fistula. Rawal Med J.2012, 37. (4): 409-411.

[15] Lindsey I, Smilgin-Humphreys MM, Cunningham C, Mortensen NJ, George BD.A randomized controlled trial of fibrin glue vs conventional treatment for anal fistula.Dis Colon Rectum. 2002; 45: 1608-15.

[16] Sahakitrungruang C, Pattana-Arun J, Khomvilai S, Tantiphlachiva K, Atittharnsakul P, Rojanasakul A. Marsupialization for simple fistula in ano: a randomized controlled trial. J Med Assoc Thai. 2011; 94(6): 699-703.

[17] Bhatti, Y, Fatima, S, Shaikh, GS. \& Shaikh S. Fistulotomy versus fistulectomy in the treatment of low fistula in ano. Rawal Med J. 2011; 36: 284-286.

[18] Pescatori, M., Ayabaca, S.M., Cafaro, D., Iannello, A.
\&Magrini, S. Marsupialization of fistulotomy and fistulectomy wounds improve healing and decreases bleeding: a randomized controlled trial. Colorectal Diseases. 2006; 8: 11-14.

[19] Anwar I, Niaz Z, Muneeb A, Cheema M, Moeen A. Fistulotomy a better treatment modality than fistulectomy for low fistula in ano. Ann King Edward Med Uni 2003; 9: 171- 2.

[20] Nazeer MA, Saleem R, Ali M, Ahmed ZN. Better Option for the Patients of Low Fistula in Ano: Fistulectomy or Fistulotomy. Pakistan J Med Health Sci. 2012, 6 (4): 885-887.

[21] Malik A.I., Nelson R.L., Surgical management of anal fistulae: a systemic review. Colorectal dis. 2008; 10: 420-30.

[22] Qureshi K.H., Kamal M., Shah H.A.,Tariq N.A. et al. Management of fistula-in-ano - a common clinical problem. Pakistan J. med. Res.2002; 41: 3.

[23] García-Aguilar J, Davey CS, Le CT, Lowry AC, Rothenberger DA. Patient satisfaction after surgical treatment for fistula-in-ano. Dis Colon Rectum 2000; 43: 1206-1212. 